\title{
RESEARCH EXPERIENCE FROM THE USE OF DIFFERENT ADDITIVES IN WOOD-FUEL PELLET PRODUCTION
}

\author{
MAGNUS STÅHL, JONAS BERGHEL \& STEFAN FRODESON \\ Environmental and Energy Systems, Karlstad University, Karlstad, Sweden.
}

\begin{abstract}
The use of wood-fuel pellets has increased significantly worldwide in recent years, especially in the United Kingdom. If wood-fuel pellets should continue to be a successful biofuel at the energy market, the pellet production industry has to reduce the production cost, since it is a low-margin business. Further, improved pellets regarding storability and strength of the pellets are crucial to manage the overseas transportation that causes material losses. In addition, the industry tries to produce pellets from a broader raw material base and at the same time satisfy the customer requirements while producing a sustainable product. The wood-fuel pellet industry has the possibility to meet all these criteria; however, it also has the potential for improvements. Using additives in pellet production is one way to meet the criteria. In conclusion, it is necessary to do the research that systematically investigates the consequences of using additives for wood-fuel pellets, and this work presents a compilation of results and experiences from more than 20 different additive studies and the test bed for pellet production research at Karlstad University- a pellet production unit adapted for additives studies. Additives, with an admixture of up to $2 \%$ (wt.), have been tested in the NewDeP (New Development for Pellet Technology) pilot plant for pellet production at Karlstad University. The research has focused on the electricity consumption, the physical and mechanical properties of the pellets, and the $\mathrm{CO}_{2}$ equivalents emitted during production. The results showed that the additives Wetland grass, Algae, Turpentine and Lignin decreased the electricity consumption in the pellet press but unfortunately also decreased the durability. The additives Resins, Molasses, White sugar, Native potato starch and Oxidized potato starch increased the durability of the pellet but showed almost no change in the electricity consumption. However, Oxidized corn starch, Spent sulphite liquor and Native wheat starch as additives increased the mechanical properties while it decreases both the electricity consumption and the climate impact, hence a Win-Win-Win situation.
\end{abstract}

Keywords: additives, $\mathrm{CO}_{2}$ equivalents, durability, electricity consumption, wood-fuel pellets

\section{INTRODUCTION}

\subsection{Wood-fuel pellets}

On the path towards a more sustainable world, the use of renewable resources should increase and replace fossil fuels. Using biomass for energy conversion is one way to go, but it is important that the resources are used efficiently. The use of wood-fuel pellets has increased significantly worldwide in recent years; especially in the United Kingdom were industry pellets for electricity production replaces coal. In 2014, the estimated global level of wood pellet production reached 27 million metric tonnes (MT) [1], and it is expected to reach approximately 50 MT by 2020 [2]. In 2014, more than $75 \%$ of the pellets were consumed in Europe [1], making Europe the largest pellet consumer in the world. The main reason behind this surge in pellet usage is the EU 2020 targets for renewable energy sources. Based on these targets, the wood pellet market in Europe is expected to grow even further [3, 4].

If wood-fuel pellets should continue to be a successful biofuel at the energy market, the pellet production industry has to reduce the production cost, since it is a low-margin business. Further, improved pellets regarding storability and strength of the pellets are crucial to 
manage the overseas transportation that causes material losses. In addition, the industry tries to produce pellets from a broader raw material base and at the same time satisfy the customer requirements while producing a sustainable product. The wood-fuel pellet industry has the possibility to meet all these criteria; however, it also has the potential for improvements.

\subsection{Objectives}

Adding different types of additives is one approach to achieve an increased energy efficiency and pellet quality. Research that systematically investigates the consequences of using additives for wood-fuel pellets could help the industries to choose the right additive for their facility. The additives used in the research presented here are mainly chosen from an environmental perspective since they are rest products from different industries. Although some of the additives are used from its ability to work as a binding agent in pellet production. This work is a compilation of results and experiences from different additive studies over almost 10 years research time. The research had its focus on the electricity consumption, the physical and mechanical properties of the pellets, and the $\mathrm{CO}_{2}$ equivalents emitted during production. Furthermore, a presentation of the possibilities our pellet production test bed, adapted for additives studies, has is presented.

\section{METHOD}

\subsection{Materials}

The raw materials used for the production of the pellets in these studies were fresh sawdust of 90\% Norway spruce (Picea abies) and 10\% Scotch pine (Pinus sylvestris). The wet sawdust was dried with air in a Stela belt dryer at a low inlet temperature of $75^{\circ} \mathrm{C}$ until it reached $10 \%$ (wb). The sawdust was ground using a $\varphi 5 \mathrm{~mm}$ vibrating screen. The dried sawdust was conditioned to $11-12 \%(w b)$ in the diagonal MAFA mixer (type D2) by adding water. Then, the sawdust was stored in the diagonal mixer for 2 days to reach uniform moisture content. The moisture content $(\%, w b)$ for the sawdust and the pellets was determined according to Ref. [5].

\subsection{Pellet production procedure}

The procedure for the tests follow the same schedule and all the additives is added in a similar way. The pilot pellet production unit is located at Environmental and Energy Systems at Karlstad University, Sweden, see Fig. 1. The pellet press (Amandus Kahl C33-390) has a flat die and for these tests, hole diameter of $8 \mathrm{~mm}$ and a maximum output of $300 \mathrm{~kg} / \mathrm{h}$.

The continuous feed pellet machine was run until stationary conditions were obtained. Before every new test, there was a break-in period with the current additive to ensure that there were stationary conditions. The feed control for the dried sawdust was set at a fixed rpm that corresponded to approximately $90-100 \mathrm{~kg}$ of sawdust/h, unsieved. Measured by weighing the produced pellets after each test run, on a Radwag WLC 12/30/C1/K weighing machine. Every pellet test run was separately cooled to ambient room temperature in a custom built cooling tower; the cooling time is less than $10 \mathrm{~min}$.

The additive flow was subsequently increased through the volumetric feeder, going up to $2.8 \%$ based on weight- $\%$ of pressing mass dry bases. The additive tested were; Algae, Rape Seed Cake, Wetland Grass, Resins, Terpenes, Lignin, Molasses, different Starch Grades, White Sugar and Spent Sulphite Liquor. 


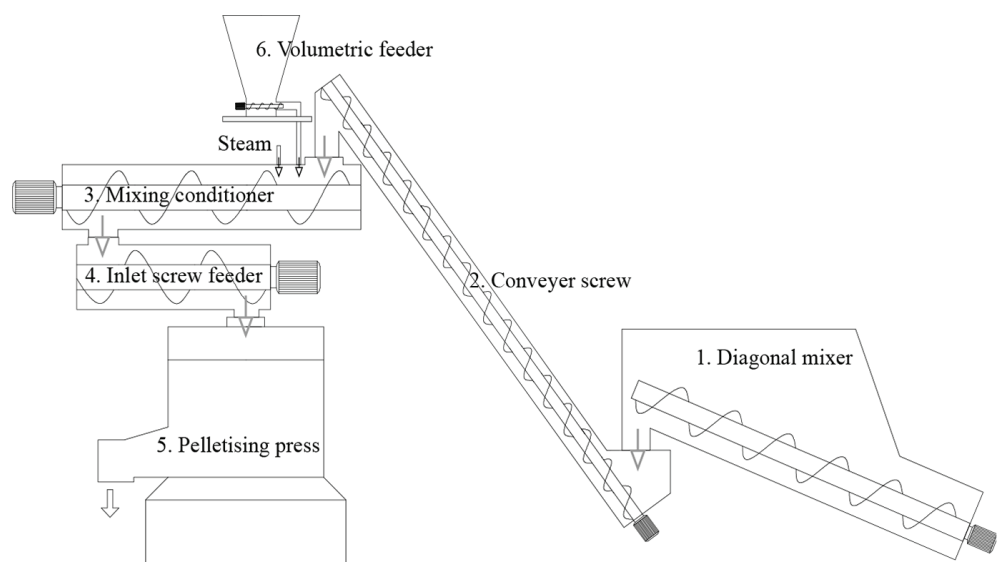

Figure 1: Description of the pellet production unit at Karlstad University.

During the tests, the die temperature, the screw frequency, the electricity consumption (current) of the pelletising machine, and the pressure from the rollers on the die ('die pressure') were measured every $10 \mathrm{~s}$. The die temperature was measured using a Pt-100 thermometer to an accuracy of $\pm 0.5^{\circ} \mathrm{C}$. The current load was measured to an accuracy of $\pm 1 \%$. From the current measured load, the electricity consumption was calculated per dry substance produced pellets according to the method described in Ref. [6]. The pressure from the rollers was measured with an accuracy of \pm 1.25 bar. The low variability of the die temperature and the pressure from the rollers indicated stationary and stable conditions.

\section{RESULTS AND DISCUSSION}

When all the additives are used in the pellet production unit, the energy use, the durability of the pellets, the $\mathrm{CO}_{2}$ eq. emissions, and the production costs are all influenced. Since NewDeP has the producers' perspective in mind when interpreting the results it meant that the additives have been categorised into three groups. These groups are connected to how valuable the results are for the producers and users of wood fuel pellets. When focusing two important factors for pellet production, the electricity consumption in the pellet press and the durability of pellets, the additives were classified like this;

1. additives that has no or little effect on the electricity consumption and the durability

2. additives that has no or little effect on the electricity consumption but showed increased durability of the pellets

3. additives that decreased the electricity consumption and increased the durability of the pellets.

Additives belonging to the first group were Wetland Grass, Algea, Turpentine, and Lignins. Algea, Turpentine and dry Lignin as additives showed almost no change in electricity use of the press and durability of the pellets. Wet Lignin and Wetland grass actually showed decreased electricity consumption but showed no change in durability regarding using Wet lignin and even a decreased durability when Wetland grass was used, see Figure 2. None of these additives are therefore suitable for pellet production.

Additives belonging to the second group were Resins, Molasses, White Sugar, Native Potato Starch and Oxidised Potato Starch. All these additives showed almost no change in 

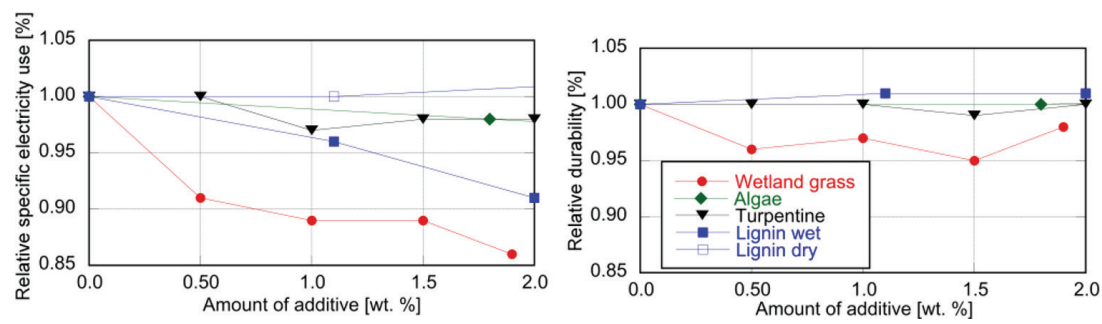

Figure 2: Change in electricity consumption and durability with increasing amounts of the additives Wetland Grass, Algea, Turpentine, and Lignins.

electricity use of the press but increased durability of the pellets; compared with pellets with no additives, see Fig. 3. If the electricity use is not a problem all these additives could be use for increasing the durability of the pellets during pellet production. It has also been found that the bulk density increased and that the amount of fines during production decreased with increasing durability, which is further important for the producers.

Additives belonging to the third group were Oxidised Corn Starch, Wheat Starch and Spent Sulphite Liquor. All these additives showed decreased electricity use of the press and increased durability of the pellets, compared with pellets with no additives, see Fig. 4. This is a win-win situation for the pellets producers.

Further improvements using additives like Oxidised Corn Starch that got the highest durability and also decreased the electricity consumption the most, could be found studying the $\mathrm{CO}_{2}$ eq. emitted. The amount of $\mathrm{CO}_{2}$ eq. emitted depends on the region that the electricity consumed in the pellet press originates from. The amount of $\mathrm{CO}_{2}$ eq. emissions also depends
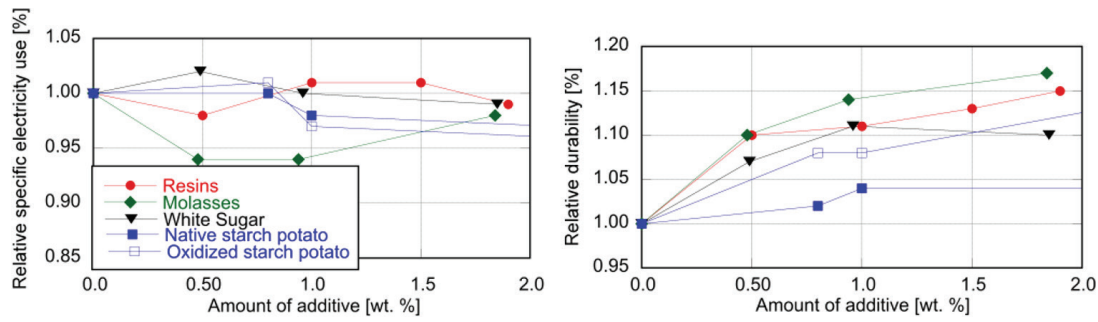

Figure 3: Change in electricity consumption and durability with increasing amounts of the additives Resins, Molasses, White Sugar, Native Potato Starch and Oxidised Potato Starch.
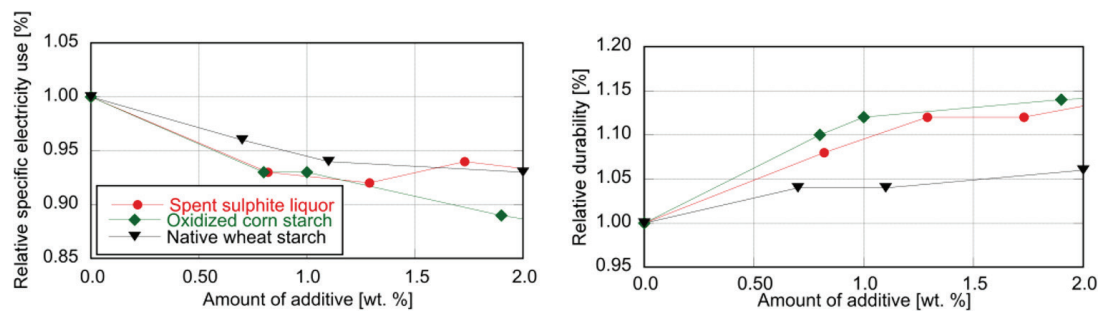

Figure 4: Change in electricity consumption and durability with increasing amounts of the additives Oxidised Corn Starch, Wheat Starch and Spent Sulphite Liquor. 


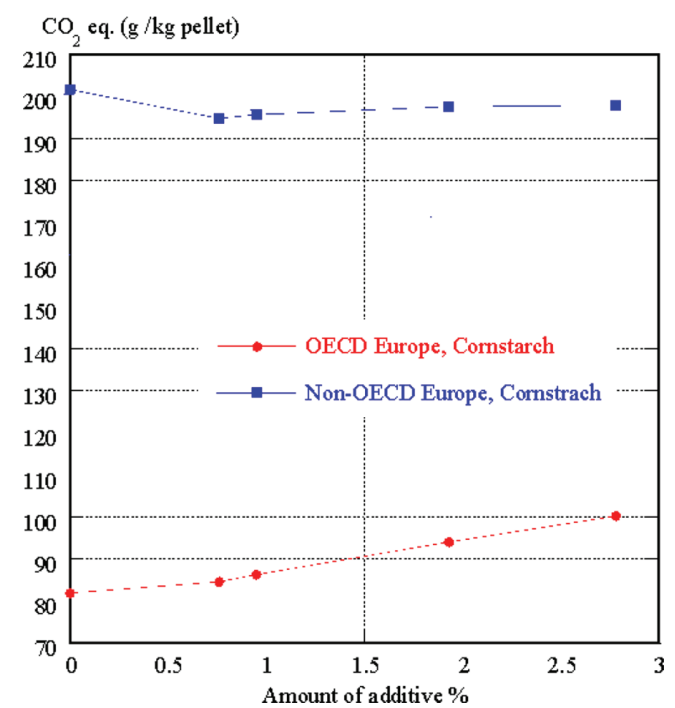

Figure 5: Emission of $\mathrm{CO}_{2}$ eq. as a function of adding the additive (wt.\%) when producing the wood pellets.

on the additives themselves, as additives with high- $\mathrm{CO}_{2}$ eq. emissions cannot be added to a large extent in the pellet production process from a global warming impact perspective. For a production unit in a non-OECD European region that mainly uses fossil fuels, the total $\mathrm{CO}_{2}$ eq. emissions decreases for Corn Starch up to an admixture of $1 \mathrm{wt} \%$, see Fig. 5. The environmental gains and quality advantages should though be balanced against the cost of the additives in the non-OECD European region.

The NewDeP (www.kau.se/pro2be/newdep-new-development-pellet-technology) test bed at Karlstad University could handle test from a few grams to $300 \mathrm{~kg} / \mathrm{h}$, that is, single pellet production to full-scale production. NewDep research encompasses how renewable material can become a high-quality pelleted product, in a sustainable and energy efficient way. The research is process oriented and covers processes from a system perspective with analyses from wet raw material to pelletized product. The research is strongly connected to applied technology and the group manage a unique test bed, in full pilot scale, with the possibility to measure and analyse the pellet process from raw material to stored pellets. A very good collaboration with the industry gives unique opportunities to scale research findings and studying data from full-scale runs. We have a well-established routine to handle the questions that come from industry and society.

\section{CONCLUSIONS}

Cornstarch as an additive increased the durability of the pellets, decreased the electrical consumption of the pellet press and could decrease the total emission of $\mathrm{CO}_{2}$ eq. if fossil fuels are used when producing the electricity used by the pellets press.

Further research is needed to find an additive that could reduce the energy used during production, decrease the environmental impact and improve the quality of the pellets, especially made from new raw materials. Further studies made in a full-scale pellet plant are also recommended to find the economically optimal amount of added additive.

The unique test bed at Karlstad University can handle/study the effects of different kind of biomaterials from wet raw materials all the way to compressed products. Our focus of 
research could concern; additives, new materials or better use of materials/waste, energy efficiency, environmental effects, new products, etc.

\section{REFERENCES}

[1] Kopetz, H., Haara, K. \& Kummamuru, B.V., WBA global bioenergy statistics, 2015. World Bioenergy Association, 2015. available at: http://worldbioenergy.org/content/ wba-launches-global-bioenergy-statistics-2015. (Accessed 18 December 2015).

[2] Mergner, S., The dynamics of global pellet markets growth prospects and price scenarios. In 4th Central European Biomass Conference, Gratz, Austria, 2014.

[3] Monteiro, E., Mantha, V. \& Rouboa, A., Portuguese pellets market: analysis of the production and utilization constrains. Energy Policy, 42, pp. 129-135, 2012. https://doi.org/10.1016/j.enpol.2011.11.056

[4] Goh, C.S., Junginger, M., Cocchi, M., Marchal, D., Thrän, D., Hennig, C., Heinimö, J., Nikolaisen, L., Schouwenberg, P.P., Bradley, D., Hess, R., Jacobson, J., Ovard, L. \& Deutmeyer, M., Wood pellet market and trade: a global perspective. Biofuels, Bioproducts and Biorefining, 7(1), pp. 24-42. https://doi.org/10.1002/bbb.1366

[5] SS-EN 14774-1, Solid biofuels - determination of moisture content - oven dry method - part 1: total moisture - reference method, SIS Förlag AB, 11880 Stockholm, Sweden, Stockholm, Sweden, 2009.

[6] Ståhl, M. \& Berghel, J., Energy efficient pilot-scale production of wood fuel pellets made from a raw material mix including sawdust and rapeseed cake. Biomass and Bioenergy, 35(12), pp. 4849-4854, 2011.

https://doi.org/10.1016/j.biombioe.2011.10.003 